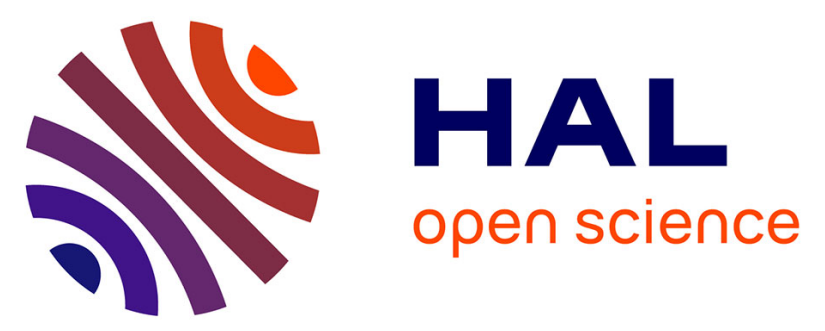

\title{
Unravelling lithiation mechanisms of iron trifluoride by operando X-ray absorption spectroscopy and MCR-ALS chemometric tools
}

\author{
F. Eveillard, C. Gervillié, C. Taviot-Guého, F. Leroux, K. Guérin, Moulay \\ Tahar Sougrati, S. Belin, D. Delbègue
}

\section{To cite this version:}

F. Eveillard, C. Gervillié, C. Taviot-Guého, F. Leroux, K. Guérin, et al.. Unravelling lithiation mechanisms of iron trifluoride by operando X-ray absorption spectroscopy and MCR-ALS chemometric tools. New Journal of Chemistry, 2020, 44 (24), pp.10153-10164. 10.1039/C9NJ06321H . hal-02992567

\section{HAL Id: hal-02992567 https://hal.science/hal-02992567}

Submitted on 20 Nov 2020

HAL is a multi-disciplinary open access archive for the deposit and dissemination of scientific research documents, whether they are published or not. The documents may come from teaching and research institutions in France or abroad, or from public or private research centers.
L'archive ouverte pluridisciplinaire $\mathbf{H A L}$, est destinée au dépôt et à la diffusion de documents scientifiques de niveau recherche, publiés ou non, émanant des établissements d'enseignement et de recherche français ou étrangers, des laboratoires publics ou privés. 


\title{
Unravelling lithiation mechanisms of iron trifluoride by operando X-ray Absorption Spectroscopy and MCR-ALS chemometric tools
}

\author{
F. Eveillard, ${ }^{a}$ C. Gervillié, ${ }^{a}$ C. Taviot-Guého, ${ }^{a}$ F. Leroux, ${ }^{a}$ K. Guérin, ${ }^{a^{*}}$ M. T. Sougrati, ${ }^{b}$ S. Belin, ${ }^{c}$ D. Delbègue ${ }^{d}$
}

The lithium-ion batteries are extensively used for electrochemical energy storage but their performances need to be continuously increased. One solution is to use alternative cathode materials such as iron trifluoride. However, its galvanostatic profile depends on the allotropic phase studied.

To go further on such various lithiation mechanisms, quick-operando XAS has been used upon reduction of anhydrous pyrochlore and rhombohedral iron fluorides. First, a fine structural characterization has been conducted by X-Ray Diffraction (XRD), ${ }^{57}$ Fe Mössbauer and Pair Distribution Function (PDF). Then, quick operando spectra have been interpreted by MCR-ALS chemometric tools enabling the identification and quantification of the different phases formed upon insertion and conversion of $\mathrm{Fe}^{3+}$ species.

\section{Introduction}

Lithium-ion batteries are key components for the novel portable application. However, their performances are limited by the cathode materials, as exemplified by $\mathrm{LiCoO}_{2}, \mathrm{LiMn}_{2} \mathrm{O}_{4}$ or $\mathrm{LiFePO}_{4}$ of specific capacity lower than $170 \mathrm{mAh} \cdot \mathrm{g}^{-1}$ in commercial cells up to now ${ }^{1}$. Many materials are good candidates to improve this capacity such as conversion type cathodes ${ }^{2}$. Among them, iron trifluoride is of particular interest with a theoretical capacity of $712 \mathrm{mAh}^{-1}$ and is the object of numerous studies ${ }^{3}$. Three polymorphs of FeF $_{3}$ exist and show different electrochemical performances: the rhombohedral form, which is the stable phase at high temperatures, the orthorhombic form also called hexagonal tungsten bronze structure $\mathrm{HTB}_{-} \mathrm{FeF}_{3}$ and the cubic pyrochlore structure. $\mathrm{HTB}_{-} \mathrm{FeF}_{3}$ is obtained most of the time with water molecules stabilized in the structural channels and is not convenient for long cycling stability ${ }^{4}$. If many studies were conducted on hydrated HTB $^{5-9}$ and hydrated pyrochlore ${ }^{10-12}$, little is known about anhydrous phases. Especially, the rhombohedral structure is less studied because of the high temperature required to obtain this structure ${ }^{4}$, however it is also the most stable as it does not exist in an hydrated form in opposite to the other structures. Yet, to overcome hydration or high temperature phase formation, solid-gas fluorination using pure molecular fluorine is the most efficient fluorination way ${ }^{13}$.

Many researchers aimed at making a connection between the voltage profiles of $\mathrm{FeF}_{3}$ and its electrochemical mechanism when the sample is used as electrode material in secondary lithium batteries. Since, such promise has yet to be realized because of challenges associated with the significant phase transformation and structural rearrangement during cycling through the combination of two electrochemical processes: insertion and conversion. To unravel electrochemical measurements, X-ray diffraction (XRD), Mössbauer and XAS, both in operando and in-situ modes are of particular interest ${ }^{14}$. Quick amorphization of iron fluoride phase during cycling does not allow any relevant analysis by in-situ nor operando X-ray diffraction ${ }^{15-18}$. By in-situ Mössbauer, only insertion mechanism was proposed for the hydrated HTB form and no structures were identified ${ }^{19}$. Finally, the most relevant characterization technique is X-ray Absorption Spectroscopy (XAS) as it allows a screening of the local environment of iron atoms.

Many theoretical studies were performed to predict the mechanism and most importantly identify the key intermediate structures: Doe et al. ${ }^{20}$ conducted DFT studies on ternary diagram Li-Fe-F and were able to predict several lithiated iron fluoride structures that could theoretically exist in a stable state depending on the potential. They predicted that the mechanism in discharge, i.e. Li insertion, goes through the total reduction of $\mathrm{Fe}^{3+}$ into $\mathrm{Fe}^{2+}$ with gradual transformation from rhombohedral $\mathrm{FeF}_{3}$ to trirutile $\mathrm{LiFeF}_{3}$ before iron cations full reduction to metallic state with simultaneous formation of a solid LiF matrix. Charge mechanism would be controlled by the slow diffusion of iron which tends to favour the direct formation of $\mathrm{Fe}^{3+}$ intermediates such as $\mathrm{Li}_{15 / 8} \mathrm{Fe}_{3 / 8} \mathrm{~F}_{3}$ or $\mathrm{Li}_{3 / 2} \mathrm{Fe}_{1 / 2} \mathrm{~F}_{3}$. They also claim that $\mathrm{FeF}_{3}$ should not be recovered after charging but rather a rutile structured $\mathrm{Li}_{3 / 4} \mathrm{Fe}_{3 / 4} \mathrm{~F}_{3}$ is expected. The differences in the reactional pathways would therefore explain the large hysteresis between charge and discharge.

However, for $\mathrm{Li}$ et $\mathrm{al}^{21}$, the origin of such discrepancy is the heterogeneity of the reaction: in opposite to previous work, they claim that the conversion reaction may start before the insertion is fully completed in the same particle. This heterogeneity leads to the hysteresis observed in electrochemical experiments. In-depth experimental studies are therefore needed to conclude on the mechanism. 
Some studies have been managed in ex-situ, but these measurements are not relevant enough to determine the exact mechanism as relaxation occurred between the current switch off and the actual measurement. In fact, as identified already by simulation in Doe et al. work ${ }^{20}$, compounds can be metastable by kinetics effects and therefore cannot be identified by ex-situ measurements as these structures would transform in other products before the delay imposed by the analysis.

Ali et al. ${ }^{18}$ performed an in-situ XAS analysis on a hydrated pyrochlore $\mathrm{FeF}_{3}$ sample but only on the insertion step: they concluded that no transformation into iron metal was observed and did not go further in the interpretation of the results.

$\mathrm{Li}$ et al. $^{22}$ succeeded in visually monitoring the topographic variation of iron oxidation degree in the sample during the conversion reaction by a coupling between SEM and XANES analyses. They analysed the results both through discharge and charge and ascribed the hysteresis to the fact that the original $\mathrm{FeF}_{3}$ was actually only partially recovered after the first cycle. However, no phases were identified and the exploitation of operando conditions is quite limited as they only reported nine measurement points over a complete cycle.

Zhang et al. ${ }^{23}$ also managed to perform an in-situ XAS monitoring of the conversion mechanism of a rhombohedral (space group R-3c) $\mathrm{FeF}_{3}$ sample. They claim that insertion occurs through a two-step mechanism during the first discharge: a two-phase reaction from 0 to $0.46 \mathrm{Li}$ with the formation of an intermediate $\mathrm{Li}_{0.46} \mathrm{FeF}_{3}$ leading to a one-phase reaction until $0.92 \mathrm{Li}$ is reached forming an $\mathrm{R} 3 \mathrm{C}$ structured $\mathrm{Li}_{0.92} \mathrm{FeF}_{3}$ compound. Domains of metallic Fe are formed only during conversion between $0.92 \mathrm{Li}$ and $2.78 \mathrm{Li}$ and have small diameters $(<1 \mathrm{~nm})$. They observed a quite symmetrical pathway for recharge with gradual Fe transformation between $2.78 \mathrm{Li}$ and $0.82 \mathrm{Li}$. However, only 14 measurement points were taken over the whole cycle. Another problem arises from the measurement methodology: to process XAS measurements, electrochemical cycling of the cell was temporarily stopped at given voltage values. This may lead to false conclusions as the electrode material can transform into other structures when no voltage is applied: the mechanism could therefore be affected.

If insertion and conversion appeared distinctly in previous studies, Li et al. ${ }^{21}$ made different observations in their in-situ XAS work. In fact, they claim that during the formation of a rutile like phase between 0 and $0.78 \mathrm{Li}$, metallic Fe also begins to form at an early stage even before reaching conversion voltage threshold. Between 0.61 $\mathrm{Li}$ and $2.15 \mathrm{Li}$, the three oxidation states of iron $(0,+\mathrm{II}$ and $+\mathrm{III})$ are present in opposite to what was demonstrated before. In the same study, they claim that hysteresis arises not from asymmetry of the mechanism between discharge and charge but rather because of heterogeneous transformation as conversion occurs before insertion is completed. The heterogeneity arises from the different nature of the reactions: while the insertion minimizes atomic displacement resulting in a topotactic reaction for $\mathrm{FeF}_{3}$ as stated by Arai et al. ${ }^{24}$, the conversion implies the total reduction of iron cations and important lattice changes. In fact, they highlighted the influence of kinetics in the mechanism, explaining the variation of voltage profiles with the morphology and the structure of the iron trifluoride sample. However, measurements were made only every 18 minutes and some key structures might have been skipped.

We can conclude from this bibliographic overview that there is a need for more reliable experimental studies as controversy still exists. Such discrepancies in the description of the electrochemical mechanism can be due to the strong influence of relaxation on the system but also on the different type of materials used in those studies. Thus, one can express doubts on the data collected through in-situ experiments presented previously. One can also observe that in the references quoted in the previous paragraph, no clear distinction is made between operando and in-situ as some authors quote operando even when just a dozen of measurement points are gathered over a whole cycle. Actually, we did not report any operando X-ray Absorption study with higher measurement frequency than Li et al. study ${ }^{21}$ with a sampling time of 18 minutes for $\mathrm{FeF}_{3}$. Operando monitoring of the lithiation of $\mathrm{FeF}_{3}$ is therefore required to figure out the mechanism with accuracy.

Our main objective was therefore to fully describe the insertion mechanism by operando XAS but also the conversion mechanism involved during the discharge of the Li-ion batteries based on $\mathrm{FeF}_{3}$ positive electrodes by exploiting XANES data giving access to the chemical state of $3 \mathrm{~d}$ transition metals such as iron but also their local environment. In particular, an interesting data treatment allowing a chemometric monitoring of the galvanostatic discharge was used in this study called Multivariate Curve Resolution with Alternating Least Squares (MCR-ALS). Indeed, it unravelled remarkable results on the lithiation mechanism of $\mathrm{Cu}$ incorporated into $\mathrm{Cu}_{0.1} \mathrm{~V}_{2} \mathrm{O}_{5}$ xerogel electrode material ${ }^{25}$.

XAS spectra were interpreted through chemometric tools permitting to analyse the huge amount of recorded data. We present here our first results with such mathematic tools obtained by the combination of Principal Component Analysis (PCA) and Multivariate Curve Resolution with Alternating Least Squares (MCR-ALS) after treatment of the analyses of two $\mathrm{FeF}_{3}$ samples used as positive electrodes during their first discharge both in insertion and conversion. The mathematical principle of this chemometric method is described in different works $^{26-29}$. Typically, Principal Component Analysis is applied to the dataset to determine the smallest number of components required to describe the reaction, then once given some conditions related to the experiment such as 
the positivity of the concentrations, the MCR-ALS enables the identification and quantification of the different species obtained by the algorithm to give the best fit possible with the experimental XAS spectrum at all times during the studied reaction: in our case, the lithiation of two different $\mathrm{FeF}_{3}$ samples.

The unique solution respecting the applied constraints gives access to the XAS spectra of the four pure components and their relative concentration evolution during the lithiation. Information such as the pseudo radial distribution corresponding to the Fourier transformation of the EXAFS part (FT-EXAFS) for each model phase or specie can also be extracted.

\section{Results and discussion}

\section{Materials synthesis and characterizations}

The materials have been either synthesized using $\mathrm{FeCl}_{3} \cdot 6 \mathrm{H}_{2} \mathrm{O}$ as a precursor for the sample called rhombohedral product in the rest of the study (denoted $r-\mathrm{FeF}_{3}$ ) and $\mathrm{NH}_{4} \mathrm{Fe}_{2} \mathrm{~F}_{6}$ for the sample called pyrochlore product (denoted pyr- $\mathrm{FeF}_{3}$ ). Figure 1 shows the results of $\mathrm{X}$-ray diffraction performed on the reaction products.

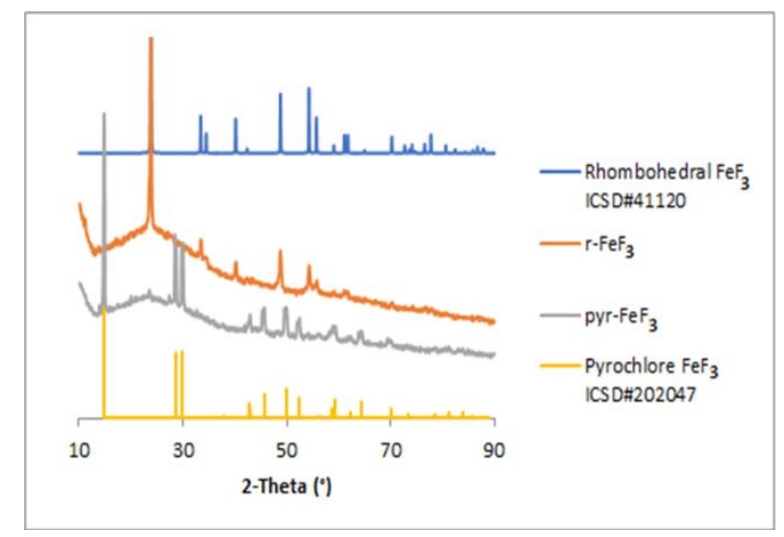

Figure 1: X-ray diffractograms of $r-\mathrm{FeF}_{3}$ and $\mathrm{pyr}-\mathrm{FeF}_{3}$ compared to theoretical diffractograms

Diffractograms confirm the presence of a crystallised phase for both products. In the case of $r$-FeF $F_{3}$, each peak can be assigned to rhombohedral $\mathrm{FeF}_{3}$ (ICSD\#41120) reference structure. However, peaks of the studied sample are broad: as exemplified around $32^{\circ}$ and $55^{\circ}$, peaks appearing as doublets in the theoretical diffractograms appear as singlets in experimental results due to this broadening. Moreover, no peak could be observed above $60^{\circ}$ due to very low intensities. This loss of information is due to a low crystallinity of the product. In the case of pyr- $-\mathrm{FeF}_{3}$, peaks of the experimental diffractogram can be assigned to cubic pyrochlore reference structure (ICSD reference structure \#202047). As well, for this sample, peaks are rather broad and the ratio noise/signal is quite high which is synonymous of a low crystallinity. Because of XRD analyses for both samples, some amorphous domains remain in the products as XRD baselines are irregular showing a large diffusion background.

Mössbauer measurements were therefore conducted to complete this structural analysis as both the crystallised and the amorphous part of the material can be analysed using this method. Spectra as well as fitting parameters such as isomeric shift (IS), quadrupole splitting (QS), full width at half maximum (FWHM), evaluated percentage of the spectral component and possible assignment to the different $\mathrm{FeF}_{3}$ structures as compared with literature ${ }^{30,31}$ are presented in Figure 2 and Figure 3. 


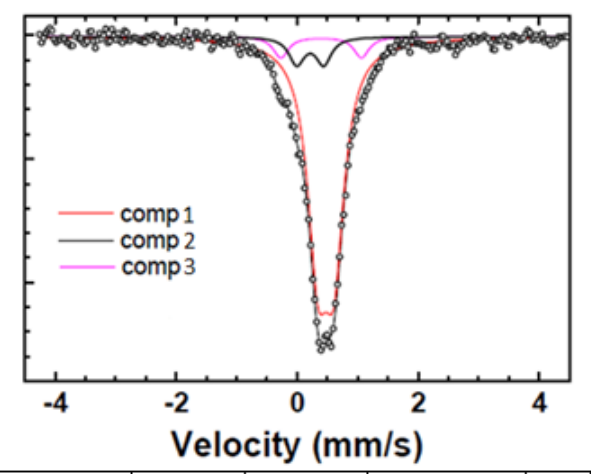

\begin{tabular}{|c|c|c|c|c|c|}
\hline Spectral component & IS (mm/s) & QS (mm/s) & FWHM (mm/s) & $\%$ & Assignment \\
\hline $\begin{array}{c}\text { comp 1 } \\
\text { (red) }\end{array}$ & 0.48 & 0.27 & 0.40 & 87.4 & $\begin{array}{c}\text { Pvcochlore FeF } \\
\text { reference phase }\end{array}$ \\
\hline $\begin{array}{c}\text { comp 2 } \\
\text { (grey) }\end{array}$ & 0.22 & 0.45 & 0.30 & 8.4 & Amorphous Fe $^{3+}$ \\
\hline $\begin{array}{c}\text { comp 3 } \\
\text { (pink) }\end{array}$ & 0.40 & 1.33 & 0.30 & 4.2 & $\begin{array}{c}\text { HTB-FeF } \\
\text { reference phase }\end{array}$ \\
\hline
\end{tabular}

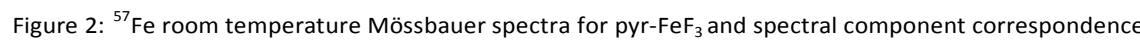

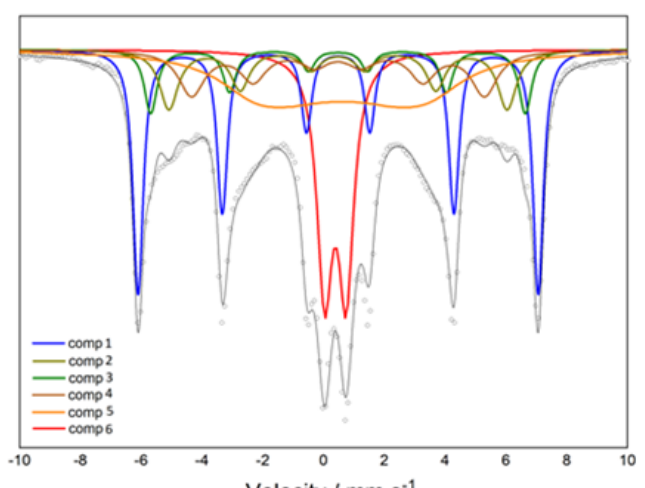

Velocity / $\mathrm{mm} \mathrm{s}^{-1}$

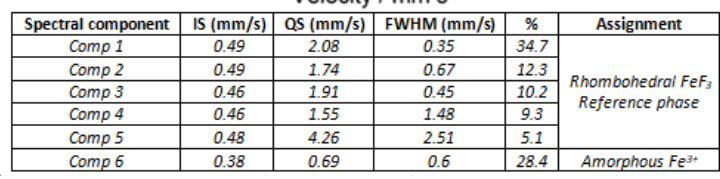

Figure $3:{ }^{57} \mathrm{Fe}$ room temperature Mössbauer spectra of the obtained powders for $\mathrm{r}-\mathrm{FeF}_{3}$ and spectral component correspondence

Mössbauer analyses confirm the formation of the major phase seen by XRD but also specify the oxidation state of iron in the amorphous phase as $\mathrm{Fe}^{3+}$ and can also detect other phases not enough crystallised to be seen by XRD. In the case of $r-\mathrm{FeF}_{3}$, no other phases were detected. In the case of pyr-FeF 3 , a majority of pyrochlore structured was found but some $\mathrm{HTB}_{\mathrm{T}} \mathrm{FeF}_{3}$ was also registered.

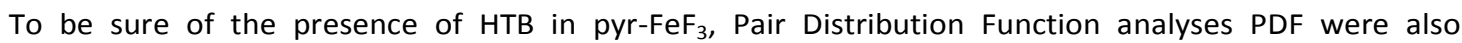
performed on this specific sample. The raw PDF data in the low r-region for this sample is displayed in Figure 4 below and compared with the simulated PDF of the cubic pyrochlore (ICSD\#202047) and HTB (ICSD\#35359) reference structures. In the low r-region, the two structures are quite similar, on the other hand they differ clearly for distances above $10 \AA$ and the pyrochlore form appears to be the predominant phase in the sample.

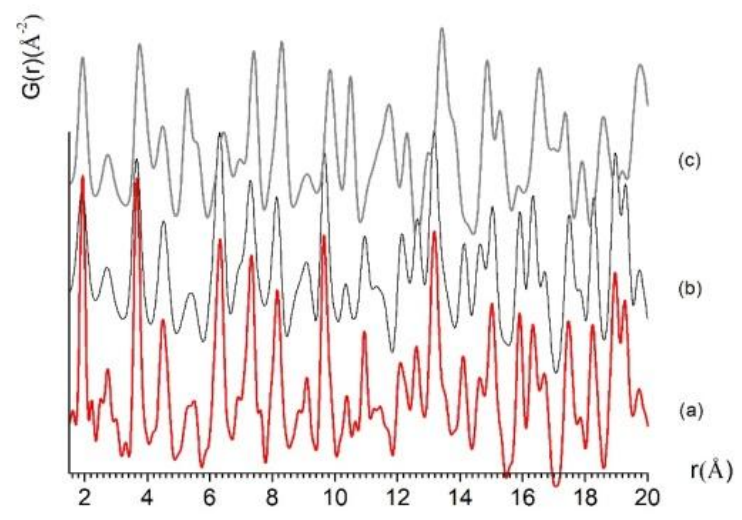




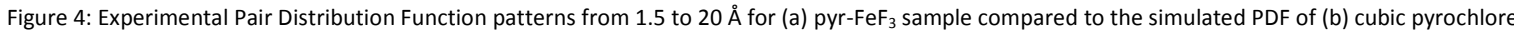
(ICSD\#202047) and (c) Hexagonal Tungsten Bronze (ICSD\#35359) $\mathrm{FeF}_{3}$ allotropic forms.

Initially, the PDF data in the 1.5-20 A r-region were fitted with the crystal structure of the pyrochlore phase and goodness of fit Rw converged to $21.4 \%$ after optimizing the scale factor, unit cell, atomic positions and Atomic Displacement Parameter ADPs. Then, the Hexagonal Tungsten Bronze HTB phase was included in the refinement, which improved the PDF fit as the Rw value decreased from $21.4 \%$ to $16.8 \%$. All the structural parameters for the HTB phase were kept fixed. The refinement of the scale factors of both phases led to the following relative phase fractions: $17.6 \%$ for $\mathrm{FeF}_{3} \mathrm{HTB}$ form and $82.4 \%$ for $\mathrm{FeF}_{3}$ pyrochlore form. The final fit is displayed in Figure 5 and the refined atomic structure data are given in TableSI.1

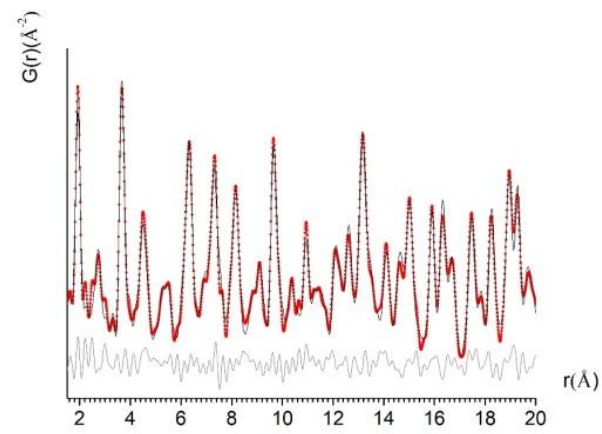

Figure 5: Experimental (red solid circle) and fitted (black solid line) PDF patterns for pyr- $\mathrm{FeF}_{3}$ in the 1.5 to 20 Å r-range considering a mixture of $17.6 \%$ FeF 3 HTB and $82.4 \%$ of $\mathrm{FeF}_{3}$ pyrochlore. Difference curve is shown as grey line.

These results are coherent with the Mössbauer results for this sample, as the pyrochlore structure represents more than $80 \%$ of the composition in both cases. This confirms the presence of a $\mathrm{HTB}^{-\mathrm{FeF}_{3}}$ domain representing between 15 and $20 \%$. In opposite to the majority of studies presented on $\mathrm{FeF}_{3}$, a deep structural study is here achieved. In the present case, HTB phase identified in pyr-FeF ${ }_{3}$ sample could not be detected by using XRD and only advanced characterizations (Mössbauer and PDF for instance) were able to accurately quantify the nature and amount of impurity. This HTB impurity in pyr- $\mathrm{FeF}_{3}$ might also exist in other published works if only XRD was performed to determine the structure and composition of their samples.

Obtained products and their compositions are summarized below in Table I.

Table I: Samples studied and their composition as confirmed by XRD, ${ }^{57}$ Fe Mössbauer and PDF

\begin{tabular}{|c|c|c|}
\hline Precursor & $\mathrm{NH}_{4} \mathrm{Fe}_{2} \mathrm{~F}_{6}$ & $\mathrm{FeCl}_{3} \cdot 6 \mathrm{H}_{2} \mathrm{O}$ \\
\hline $\begin{array}{c}\text { Sample } \\
\text { notation }\end{array}$ & Pyr-FeF 3 & $\mathrm{r}-\mathrm{FeF}_{3}$ \\
\hline Composition & $\begin{array}{l}\text { 82.4\% Pyr-FeF } \\
\text { 17.6\% } \mathrm{HTB}_{3}-\mathrm{FeF}_{3}\end{array}$ & $\begin{array}{c}71.6 \% \mathrm{r}-\mathrm{FeF}_{3} \\
28.4 \% \text { amorphous } \\
\mathrm{Fe}^{3+}\end{array}$ \\
\hline
\end{tabular}

Electrochemical tests were made in routine conditions, i.e low current densities of $20 \mathrm{~mA} / \mathrm{g}(\mathrm{C} / 24$ if $\mathrm{C}$ refers to the whole 3 electron process) in galvanostatic mode, to observe the behavior of the prepared samples. Results are discussed in the following part.

\section{Electrochemical tests}

First, we studied the electrochemical behaviours of $r-\mathrm{FeF}_{3}$ and pyr- $\mathrm{FeF}_{3}$ samples in their first complete reduction along with the derivative curve to identify the critical steps (Figure 6).

On both curves in Figure 6 a), two different reactions can be observed and are separated by a break in the curve at about $1.8 \mathrm{~V}$ vs. $\mathrm{Li}^{+} / \mathrm{Li}$. Owing to Cosandey et al. $^{32}$, it allows to delimitate the insertion step from the conversion one. These reactions can be summed up by the following equations:

$$
\begin{array}{cc}
x \mathrm{Li}^{+}+\mathrm{xe} \mathrm{e}^{-}+\mathrm{FeF}_{3}->\mathrm{Li}_{\mathrm{x}} \mathrm{FeF}_{3} & \text { insertion step } \\
(3-\mathrm{x}) \mathrm{Li}^{+}+(3-\mathrm{x}) \mathrm{e}^{-}+\mathrm{Li}_{\mathrm{x}} \mathrm{FeF}_{3}->3 \mathrm{LiF}+\mathrm{Fe}^{\circ} & \text { conversion step }
\end{array}
$$

Both the galvanostatic curves and its derivatives tend to indicate that electrochemical mechanisms between the two $\mathrm{FeF}_{3}$ samples are different in the insertion step and the conversion one: in fact, the reaction begins at a 
slightly higher voltage for pyr-FeF 3 than for $r-\mathrm{FeF}_{3}$. According to the derivative presented in Figure $6 \mathrm{~b}$ ), there could be a three-step reaction in insertion in the case of pyr- $\mathrm{FeF}_{3}$ as the derivative curve presents two distinct peaks around 3.15 and $2.75 \mathrm{~V}$ respectively. In opposite, only one peak at $3.05 \mathrm{~V}$ is registered for $\mathrm{r}-\mathrm{FeF}_{3}$, thus highlighting the possibility that mechanism differs with $\mathrm{FeF}_{3}$ sample. The difference is also present in the conversion step: $r$ $\mathrm{FeF}_{3}$ sample presents higher lithium content in conversion than pyr-FeF $\mathrm{F}_{3}$ for a $1 \mathrm{~V}$ cut-off voltage. $r-\mathrm{FeF}_{3}$ sample

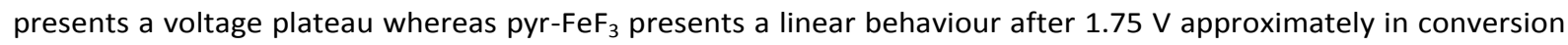

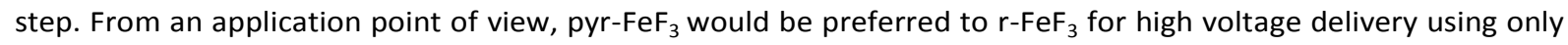
insertion process (capacity up to about $200 \mathrm{mAh} / \mathrm{g}$ ). For high capacity specification (up to $700 \mathrm{mAh} / \mathrm{g}$ ), r-FeF 3 would be selected for its higher capacity at higher usable voltage.

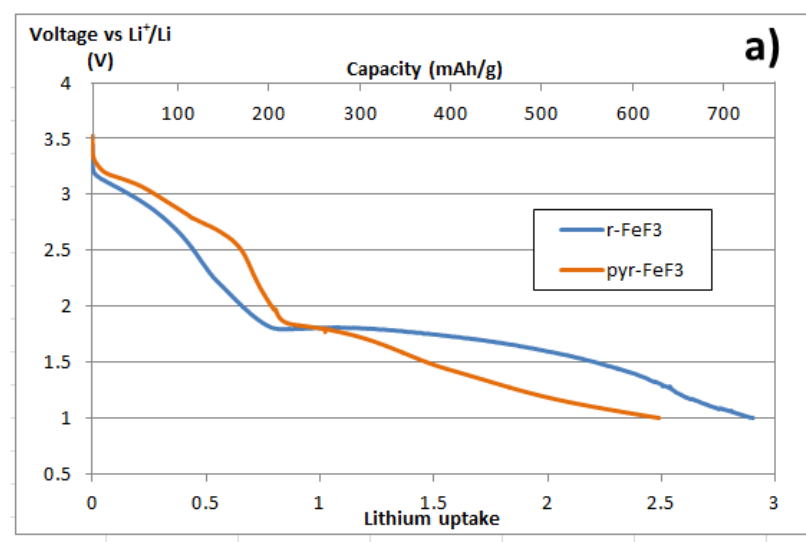

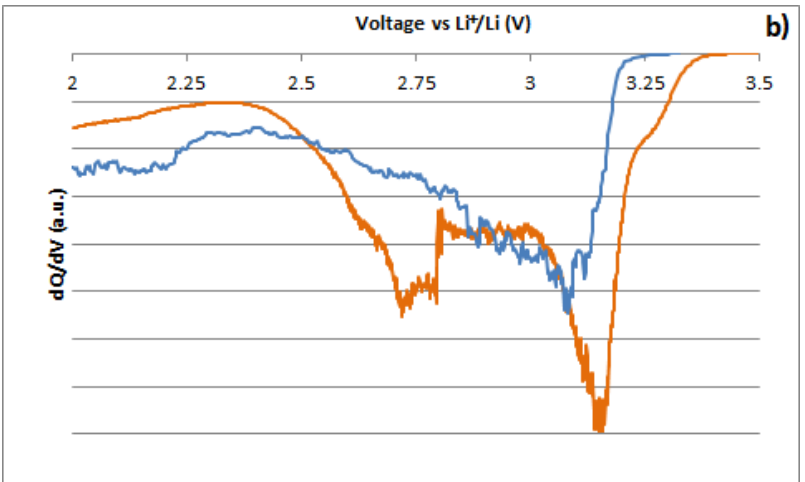

Figure 6: a) Discharge of both samples upon insertion and conversion processes

b) corresponding derivatives $\mathrm{dQ} / \mathrm{dV}$ for the insertion step

From these voltage profiles, one may question the influence of HTB phase in pyr-FeF $F_{3}$. On one hand, the fact that insertion ends at the same voltage and lithium uptake for $r-\mathrm{FeF}_{3}$ and $\mathrm{pyr}-\mathrm{FeF}_{3}$ samples implies that whatever the crystallographic origin of $\mathrm{Fe}^{3+}$ (rhombohedral, pyrochlore, HTB phases or even amorphous), insertion occurs. On the other hand, pyr- $\mathrm{FeF}_{3}$ could not complete the whole conversion in the imposed electrochemical window. We are unable at this point to determine if this is only due to the pyrochlore crystallographic form or to the HTB impurity or both. All these elements justify the need for a depth investigation of the electrochemical mechanism of both samples by operando methods and especially XAS as XRD is useless since iron trifluorides undergo amorphization during the process. Results are presented in the next part.

\section{Operando XANES - EXAFS}

\section{Comparative discharge mechanism}

The reduction mechanism of pyr- $-\mathrm{FeF}_{3}$ and $\mathrm{r}-\mathrm{FeF}_{3}$ samples were monitored by operando XAS both on insertion and conversion step. Galvanostatic mode was run to gather data. A special electrochemical cell ${ }^{33}$ was used for the operando monitoring of the reaction.

A spectrum was collected every 0.5 seconds, thus giving a real operando monitoring of the reaction. To reduce the tremendous amount of data to treat, an average of 57 spectra was made after ensuring all of them had the same outline, resulting in an effective sampling time of around 30 seconds, which is more precise than the literature quoted in the introduction.

The PCA analysis indicated that 4 independent components are needed to describe the thorough evolution of the local environment around Fe atoms during both the insertion and the conversion process. After that, the treatment using the number of 4 principal components determined by PCA used as the basis for MCR-ALS analyses was followed (See Fig.SI 1). As shown by the comparison of the XANES spectra of $r-F_{3} F_{3}$, pyr-FeF 3 and HTB phase presented in SI (Fig.SI 2), these compounds have very similar local arrangements at the pristine state. From such similarities, we stated that pyr- $\mathrm{FeF}_{3}$ could be treated as one single contribution for MCR-ALS treatment. One has to keep in mind that the 4 phases used for this sample might be a mixture of different sub phases resulting from inhomogeneous electrochemical reactions or from the presence of HTB in the pyrochlore major phase.

XANES spectra analyses allow the screening of the oxidation state, which is of particular interest in our case as it varies during electrochemical reaction. The XANES spectra of the 4 phases obtained by MCR-ALS method are presented below for both compounds. 


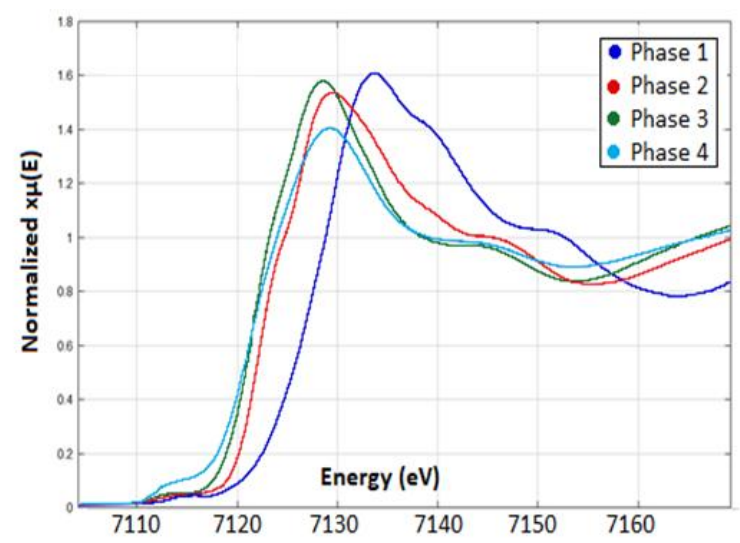

Figure 7: XANES spectra of the four phases obtained by MCR-ALS for pyr-FeF 3

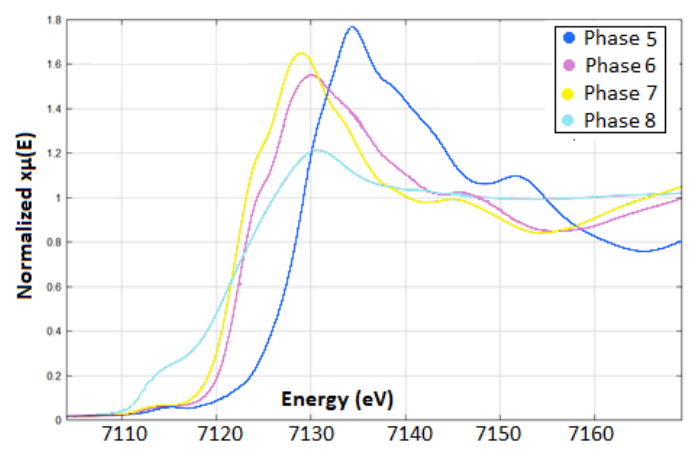

Figure 8: XANES spectra of the four phases obtained by MCR-ALS for $\mathrm{r}-\mathrm{FeF}_{3}$

With reduction, phase 1 or phase 5 corresponding respectively to pyr- $\mathrm{FeF}_{3}$ and $r-\mathrm{FeF}_{3}$, is progressively

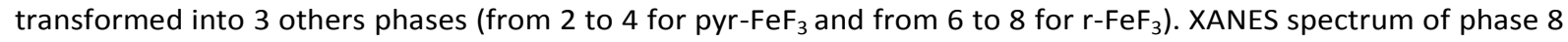
has a very different shape than phases 5, 6 and 7: by comparison with references, it was demonstrated that this phase presented similarities with metallic iron (see fig SI.2).

We may assume that, apart from phase 8 , all products have roughly the same environment since a gradual shift of the XANES experimental spectra white lines toward lower energy values is observed. This corresponds to the galvanostatic reduction of $\mathrm{FeF}_{3}$ thus validating somehow the coulometric titration directly related to iron cations redox reactions.

During the discharge, the relative concentration variations of the four phases used as models for experimental XAS spectrum fitting determined by MCR-ALS are reported on Figure 9. For both compounds, the evolution of concentration of the four phases versus the voltage of the reaction is plotted to clearly point out the critical voltage points, to clarify any differences in the mechanism and to compare these results with the literature.

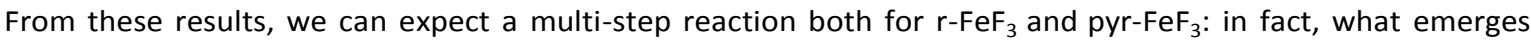
from these analyses is the presence of 2 intermediates for both $\mathrm{FeF}_{3}$ samples during cycling. Among the four phases obtained for each sample, two of them are produced and totally consumed before reaching the limits of the voltage window studied. As it is the case for phases 2 and 3 for pyr- $-\mathrm{FeF}_{3}$, and 6 and 7 for $r-\mathrm{FeF}_{3}$, these phases are intermediates in discharge reaction.

For $r-\mathrm{FeF}_{3}$ and $\mathrm{pyr}-\mathrm{FeF}_{3}$, a very similar outlook of the relative concentration evolution for the four phases chosen for each crystalline structure is observed (phases 1, 2, 3, 4 for pyr-FeF $F_{3}$, phases 5, 6, 7, 8 for $r-\mathrm{FeF}_{3}$ ): this may imply a similar mechanism for both compounds and therefore infirm the first hypothesis made based on the comparison of the galvanostatic curves in Figure 6a about different mechanisms as a function of the crystalline structure.

Concentration variations curves for lithiated phases of the pristine $r-\mathrm{FeF}_{3}$ and those selected for the pristine pyr-FeF $F_{3}$ are consistently shifted: this shift is systematically toward higher voltage values for $r-\mathrm{FeF}_{3}$. As a result, $r-$ $\mathrm{FeF}_{3}$ reacts faster than pyr- $\mathrm{FeF}_{3}$. This shift is even clearer when reaching conversion step and is consistent with Figure 6 based on the differences in galvanostatic results below $2 \mathrm{~V}$ as the pristine $\mathrm{r}-\mathrm{FeF}_{3}$ reacts with 3 lithiums uptake in opposite to 2.5 for pyr-FeF 3 .

We tried also to link the relative molar concentration profiles obtained by MCR-ALS with remarkable voltage points gathered on the derivative curve of the galvanostatic measurements (Figure 10). The composition of the 
system as a function of the voltage is presented in Table II. MCR-ALS approximations were taken into account and the closest specific event was assigned for each voltage point gathered.

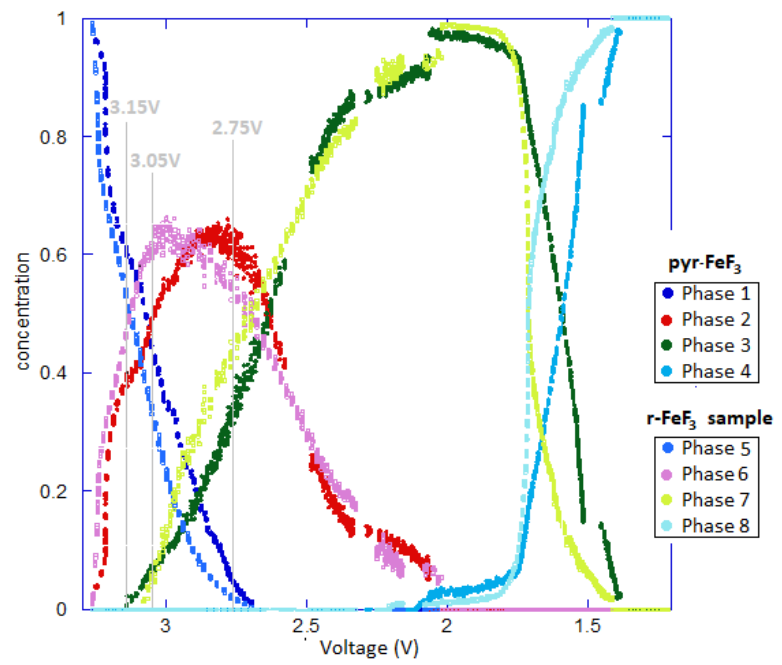

Figure 9: Evolution of the concentration of the 4 phases for $r-\mathrm{FeF}_{3}$ and pyr-FeF 3 versus voltage $(\mathrm{V})$

In the case of the rhombohedral sample, the remarkable point at 3.05V in the derivative curve dQ/dV (Figure 6b) would correspond in the MCR-ALS results in Figure 9 to the maximum of concentration at around $65 \%$ for phase 6 (purple curve) and the appearance of phase 7 (yellow curve). This point is reported on Figure 10 with a corresponding lithium uptake of $0.13 \mathrm{Li}$. This appears as a key point between two distinct reactions in the insertion step, reminding the work of Zhang et $\mathrm{al}^{23}$. They claimed that insertion step is separated into two reactions: a twophase reaction between $x=0$ and $x=0.46 \mathrm{Li}$ and a one-phase reaction between $x=0.46 \mathrm{Li}$ and $\mathrm{x}=0.92 \mathrm{Li}$. In our case however, the second intermediary begins to form while there is still some $\mathrm{FeF}_{3}$ left. According to our results, two parallel reactions could take place between $3.05 \mathrm{~V}$ and $2.75 \mathrm{~V}$ and lithium ions uptake values are very different from those reported by Zhang et al. As explained in their work, this could be linked to the influence of the morphology of the samples on the mechanism kinetics, giving very different lithium uptake values for the different events as a function of particles shape.

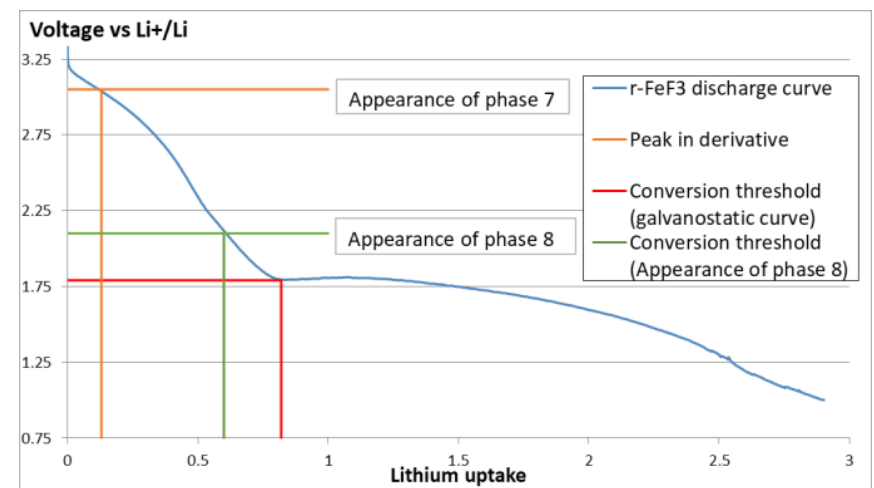

Figure 10: Galvanostatic discharge of $r-\mathrm{FeF}_{3}$ sample and links between specific voltage points and MCR-ALS events

Table II: Corresponding composition of the electrode material by voltage range for $r-\mathrm{FeF}_{3}$

\begin{tabular}{|l|c|c|c|c|}
\hline Voltage & $>3.05 \mathrm{~V}$ & $\begin{array}{c}\text { Between } \\
3.05 \mathrm{~V} \\
\text { and } \\
2.75 \mathrm{~V}\end{array}$ & $\begin{array}{c}\text { Between } \\
2.75 \mathrm{~V} \text { and } \\
2.1 \mathrm{~V}\end{array}$ & $\begin{array}{c}\text { Below } \\
2.1 \mathrm{~V}\end{array}$ \\
\hline $\begin{array}{l}\text { Present } \\
\text { phases }\end{array}$ & $\begin{array}{c}\mathrm{r}-\mathrm{FeF}_{3} \\
(\text { Phase 5) } \\
\text { Phase 6 }\end{array}$ & $\begin{array}{c}\mathrm{FeF}_{3} \\
\text { Phase 5) } \\
\text { Phase 6 } \\
\text { Phase 7 }\end{array}$ & $\begin{array}{c}\text { Phase 6 } \\
\text { Phase 7 }\end{array}$ & Phase 7 \\
& & & \\
\hline
\end{tabular}

The second remarkable point is the beginning of the conversion step: according to galvanostatic results, it should occur below $2 \mathrm{~V}$ as a plateau is observed. The main product of the conversion step is metallic iron and is the 
last specie to be formed during discharge: if we assume that phase 8 is metallic iron as assessed by XAS analysis in Figure 8 (see Fig SI. 2), this phase should start emerging in MCR-ALS only in conversion step. This is in contradiction with the statement made from galvanostatic results. In fact, we can observe on the MCR-ALS results on Figure 9 that phase 8 appears before reaching the plateau below $2 \mathrm{~V}$. However, it remains at very low concentration values below $5 \%$ before a drastic increase in quantity triggered around $1.75 \mathrm{~V}$. This observation confirms $\mathrm{Li}^{\text {et }} \mathrm{al}^{21}$ affirmation stating that metallic iron can appear before insertion step has ended, i.e. at a higher voltage than the $2 \mathrm{~V}$ limit. In fact, they observed that metallic iron appeared at a lithium uptake of $0.61 \mathrm{Li}$, which is consistent with the observation from Figure 9. Still, metallic iron remains in very low quantity until reaching the conversion step threshold observed on the galvanostatic curve, i.e. 1.75V according to both Figure 6 and Figure 10.

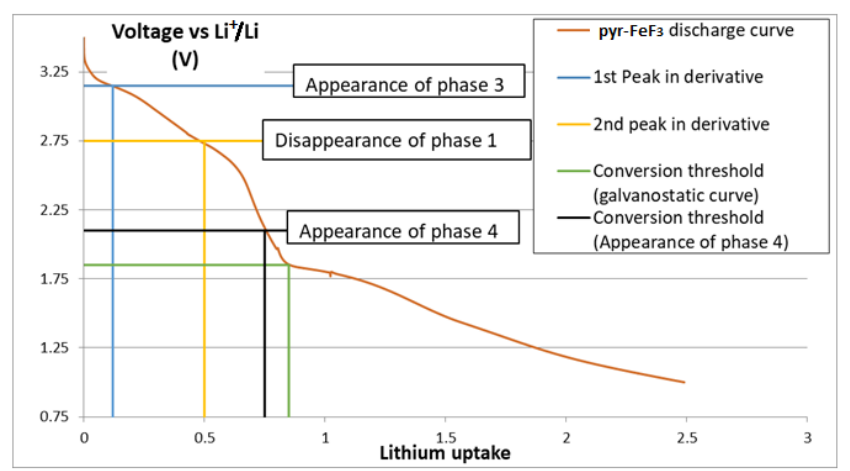

Figure 11: Galvanostatic discharge of pyr- $-\mathrm{FeF}_{3}$ sample and links between specific voltage points and MCR-ALS events

Table III: Corresponding composition of the electrode material by voltage range for pyr- $\mathrm{FeF}_{3}$

\begin{tabular}{|c|c|c|c|c|}
\hline Voltage & $>3.15 \mathrm{~V}$ & $\begin{array}{c}\text { Between } \\
3.15 \mathrm{~V} \text { and } \\
2.75 \mathrm{~V}\end{array}$ & $\begin{array}{c}\text { Between } \\
2.75 \mathrm{~V} \text { and } \\
2.1 \mathrm{~V}\end{array}$ & \begin{tabular}{|c} 
Below \\
$2.1 \mathrm{~V}$
\end{tabular} \\
\hline $\begin{array}{c}\text { Present } \\
\text { phases }\end{array}$ & $\begin{array}{c}\mathrm{FeF}_{3} \\
\text { Phase } 2\end{array}$ & $\begin{array}{c}\text { FeF }_{3} \\
\text { Phase } 2 \\
\text { Phase } 3\end{array}$ & $\begin{array}{l}\text { Phase } 2 \\
\text { Phase } 3\end{array}$ & \begin{tabular}{|l} 
Phase 3 \\
Phase 4
\end{tabular} \\
\hline
\end{tabular}

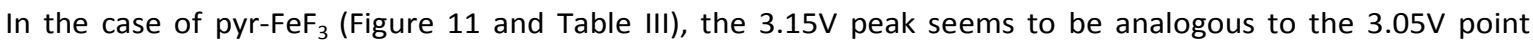
observed in the case of the $\mathrm{r}-\mathrm{FeF}_{3}$ : indeed, the $3.15 \mathrm{~V}$ point in the derivative curve (Figure $6 \mathrm{~b}$ ) is linked with the appearance of phase 3 in the MCR-ALS results. As for the $2.75 \mathrm{~V}$ voltage, it could correspond to the complete consumption of the original $\mathrm{FeF}_{3}$ (phase 1 ) and also to the maximum of phase 2 concentration around $65 \%$. Remarkable voltage points gathered from the derivative curve of the galvanostatic profile correspond therefore to

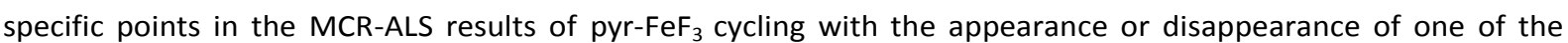
phases. For the conversion step, the observations are the same than for the pristine rhombohedral sample: phase 4 appears at the same point than phase 8 . It remains at very low concentration values until reaching $1.8 \mathrm{~V}$, the actual voltage threshold according to the galvanostatic curve of the pristine pyrochlore sample in Figure 6a.

From these links between the remarkable voltage points taken from the derivative curve of the galvanostatic measurements in Figure 6a and MCR-ALS results, it was stated that these voltage points correspond to particular points in the MCR-ALS results, thus enabling to address the mechanism, i.e Li potential sites: yet, $r-F_{3} F_{3}$ does not present two distinct points in insertion but one. This would mean that all phase transitions observed in MCR-ALS results are not significant for $\mathrm{r}^{-} \mathrm{FeF}_{3}$ as they are not systematically identified in the galvanostatic curve. For both samples, the appearance of the second reaction intermediate, i.e phase 3 for pyr-FeF $\mathrm{F}_{3}$ and phase 7 for $r-\mathrm{FeF}_{3}$ is found as a peak in the derivative curve of the galvanostatic discharge in Figure $6 \mathrm{~b}$. However, for pyr- $\mathrm{FeF}_{3}$, an additional peak is observed corresponding to the maximum of phase 2. A possible explanation is that the transition from phase 2 to phase 3 is more difficult to proceed for pyr-FeF 3 than from phase 6 to phase 7 for $r-F_{3} F_{3}$.

By relating the lithium uptake of different points of the galvanostatic curves and the corresponding composition reported at the same voltage on Figure 9, it allows the determination of the lithiation degree for each phase.

Table IV: Values of lithium uptake for each phase used in MCR-ALS for pyr-FeF $F_{3}$ and comparison with the literature ${ }^{20}$

\begin{tabular}{|c|c|c|}
\hline $\begin{array}{c}\text { Pyrochlore } \\
\text { sample }\end{array}$ & $\begin{array}{c}\text { Lithiation } \\
\text { degree }\end{array}$ & $\begin{array}{c}\text { Possible corresponding } \\
\text { phase }\end{array}$ \\
\hline
\end{tabular}




\begin{tabular}{|c|c|c|c|}
\hline & \multirow{2}{*}{$\begin{array}{c}\text { This work } \\
\text { Experimental }\end{array}$} & \multicolumn{2}{|c|}{ Literature } \\
\cline { 3 - 4 } & 0.3 & $\mathrm{Ei}_{0.46} \mathrm{FeF}_{3}{ }^{23}$ & $\mathrm{Li}_{0.25} \mathrm{FeF}_{3}$ \\
\hline Phase 2 & 0.86 & $\begin{array}{c}\mathrm{Li}_{0.92} \mathrm{FeF}_{3}{ }^{23} \\
\mathrm{Li}_{0.79} \mathrm{FeF}_{3}{ }^{21}\end{array}$ & $\mathrm{LiFeF}_{3}$ \\
\hline Phase 3 & 1.84 & No match & No match \\
\hline Phase 4 & \multicolumn{3}{|c}{} \\
\hline
\end{tabular}

Table V: Values of lithium uptake for each phase used in MCR-ALS for $\mathrm{r}-\mathrm{FeF}_{3}$ and comparison with the literature ${ }^{20}$

\begin{tabular}{|c|c|c|c|}
\hline \multirow{2}{*}{$\begin{array}{c}\text { Rhombohedra } \\
\text { I }\end{array}$} & $\begin{array}{c}\text { Lithiation } \\
\text { degree }\end{array}$ & \multicolumn{2}{|c|}{$\begin{array}{c}\text { Possible corresponding } \\
\text { phase }\end{array}$} \\
\cline { 2 - 4 } & $\begin{array}{c}\text { This work } \\
\text { Experimental }\end{array}$ & \multicolumn{2}{|c|}{ Literature } \\
\cline { 3 - 4 } & 0.07 & Experimental & Simulation \\
\hline Phase 6 & 0.65 & $\mathrm{Li}_{0.79} \mathrm{FeF}_{3}{ }^{21}$ & $\mathrm{Li}_{0.5} \mathrm{FeF}_{3}$ \\
\hline Phase 7 & 2.55 & No match & No match \\
\hline Phase 8 & &
\end{tabular}

First, it was possible to attribute some intermediates observed in the literature to intermediates of this work for both crystalline structures studied, i.e pyr- $\mathrm{FeF}_{3}$ and $\mathrm{r}-\mathrm{FeF}_{3}$ when only the rhombohedral structure is represented in the references quoted. This comforts the similarity in the mechanism for the pyrochlore and the rhombohedral structure in general. In the present study, we found more correspondence with the literature for our pyr- $\mathrm{FeF}_{3}$ as shown in Table IV than for our $\mathrm{r}-\mathrm{FeF}_{3}$ as shown in Table V. Our hypothesis is that the differences observed between the two types of structure are more due to differences in the morphology between our samples than in their crystalline structure. The effect of the morphology on the voltage profile and the mechanism was already depicted in Li et al. work ${ }^{21}$.

Differences between the lithiation values of the phases for pyr- $\mathrm{FeF}_{3}$ and for $\mathrm{r}-\mathrm{FeF}_{3}$ were also observed. In the case of the $\mathrm{pyr}_{-} \mathrm{FeF}_{3}$, the two intermediates (phase 2 and phase 3 ) are in better agreement with the literature $\left(x \mathrm{Li}=0.25\right.$ and $\mathrm{xLi}=1$ are respectively reported from Doe et al simulation work ${ }^{20}$ ). Those two intermediates lead to two transition peaks in the derivative curve present in Figure $6 \mathrm{~b}$. Phase 4 could not be assigned to any identified compounds in the literature. Two possible explanations can be given: either a new intermediate was identified at the mid-range of conversion step, between $\mathrm{LiFeF}_{3}$ and metallic Fe, or the phase used by MCR ALS is actually a mix of $\mathrm{LiFeF}_{3}$ and metallic Fe. Looking at the XANES shape of phase 4, the second hypothesis is more realistic as the shape is rather similar to the previous phases formed. The percentage of metallic iron may be so little that its presence in phase 4 could not be recovered in phase 4 XANES spectra. This might arise from slow kinetics of reaction of this sample: a complete conversion may however be expected by lowering the cut-off voltage for pyr$\mathrm{FeF}_{3}$ sample.

Phases 6 and 7 of $r-\mathrm{FeF}_{3}$ cycling do not match with any references of the literature. A possible explanation is that they have very similar local structures and react in a topotactic way: phase 6 is formed shortly after the beginning of the lithiation process and would enable a smooth transition between $r-\mathrm{FeF}_{3}$ and phase 7 . In this case, only one crystalline transition exists: this is coherent with the presence of only one peak in the derivative curve presented in Figure $6 \mathrm{~b}$. As for phase 8 , the lithium uptake value is quite close to $\mathrm{xLi}=3$, confirming the presence of metallic iron as observed on its XANES spectrum in Figure 8.

To confirm our hypothesis on the mechanism, we present the four pseudo radial distributions corresponding to each of the XAS signal of the four phases obtained by MCR-ALS to fit the actual XAS signal obtained for both ther$\mathrm{FeF}_{3}$ and pyr- $\mathrm{FeF}_{3}$ samples.

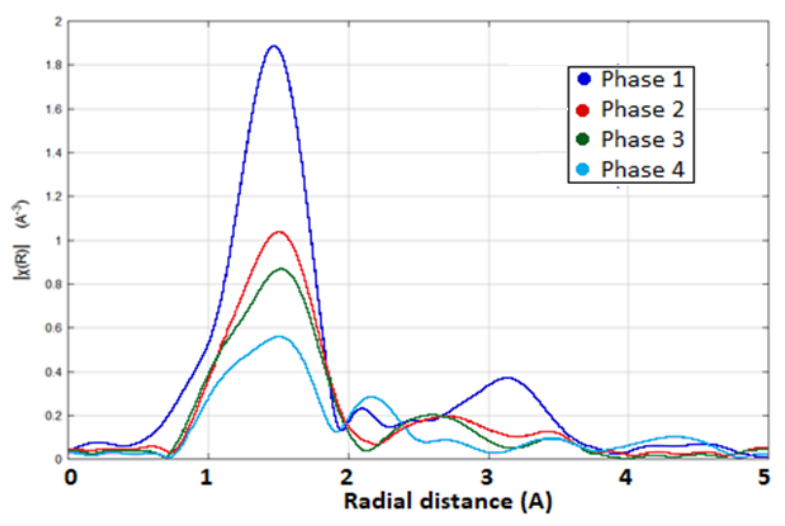

Figure 12: Fourier transforms of the four phases obtained to fit the XAS signal for pyr-FeF 3 (distances not phases corrected) 


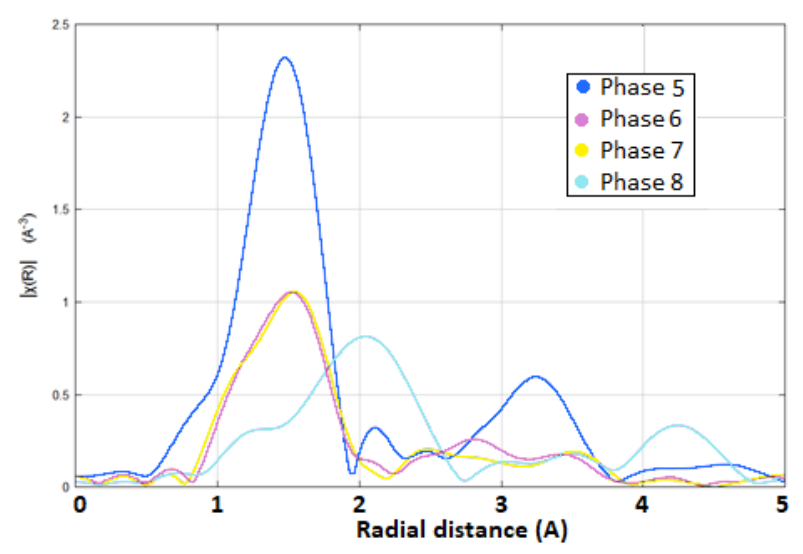

Figure 13: Fourier transforms of the four phases obtained to fit the XAS signal for $r-\mathrm{FeF}_{3}$ (distances not phases corrected)

By comparing phase 1 with phase 5 radial distributions, a similar shape is observed. As XANES spectra direct exploitation exposed previously, these phases were assigned to pyr- $\mathrm{FeF}_{3}$ and $r-\mathrm{FeF}_{3}$, respectively. The fact that both structures present similar radial distribution highlights the similarities between both crystalline structures in which iron atoms have roughly the same local environment at similar distances in both structures. In pristine rhombohedral $\mathrm{FeF}_{3}$, an iron atom is surrounded by 6 fluorine atoms at a $1.923 \AA$ distance in octahedral configuration linked by the edges. Similarly, in pristine pyr- $\mathrm{FeF}_{3}$, an iron atom is surrounded by 6 fluorine atoms at a $1.927 \AA$ A distance also in octahedral configuration as reported by De Pape et $\mathrm{al}^{34}$.

By comparing the radial distributions of phase 1 and 5 with the intermediate phases, i.e phases 2 and 3 and phases 6 and 7 respectively for pyr- $-\mathrm{FeF}_{3}$ and $\mathrm{r}-\mathrm{FeF}_{3}$, a gradual extinction of the peak corresponding to the second sphere of coordination is observed around 3.2 A. Indeed, as the discharge proceeds, the intensity of this peak keeps on decreasing: this is synonymous of a gradual loss of local atomic order as a function of the lithium uptake. It can be correlated to the loss of crystallinity observed in all in-situ XRD study produced to the best of our knowledge during $\mathrm{FeF}_{3}$ discharge: a collapse of the crystalline network is systematically observed. This decrease of intensity in pseudo radial distributions also confirms a decrease of coherence length even at the molecular scale. Therefore, the lithiation process acts as a grinder for $\mathrm{FeF}_{3}$ not only at the microscale of the material but also at the nanoscale.

When comparing the last phases formed in each case, i.e. phase 4 and 8 respectively for $p y r-\mathrm{FeF}_{3}$ and $r-\mathrm{FeF}_{3}$, we can see that final products are very different. By comparison with references, it was already assessed that XANES spectrum of phase 8 presents similarities with metallic iron, thus confirming the hypothesis that metallic iron is formed at low voltage through conversion step for the rhombohedral sample. However, phase 4 XANES spectrum does not present such similarities. For pyr- $\mathrm{FeF}_{3}$, phase 4 pseudo radial distribution presents a new peak around $2.2 \AA$ which is assigned to metallic iron: its intensity is however quite low. If we consider that this peak can be attributed to metallic iron, this would confirm the hypothesis made for this sample: phase 4 can actually be a mix of a very small quantity of metallic iron and $\mathrm{FeF}_{2}$. We explain the differences in results for pyr-FeF $\mathrm{F}_{3}$ and $\mathrm{r}-\mathrm{FeF}_{3}$ by differences of kinetics: as observed in Figure 6 and stated earlier, $r-\mathrm{FeF}_{3}$ is able to go further in conversion step than pyr- $-\mathrm{FeF}_{3}$, approaching a maximum 3 electron exchange at the end of the reduction versus 2.5 for pyr-FeF $\mathrm{F}_{3}$. This explains the different XAS spectra of the last phases formed as a function of the sample studied. These differences between phase 4 and phase 8 are coherent with the previous observation made from the lithium uptake values.

As for the intermediates, in the case of $\mathrm{pyr}^{-\mathrm{FeF}_{3}}$, phase 2 and phase 3 present rather different radial distributions: this would explain the fact that this transformation is identified in the galvanostatic curve as a peak in the derivative at $2.75 \mathrm{~V}$ when the maximum of phase 2 is reached. In opposite, in the case of the rhombohedral sample, phase 6 and phase 7 have very similar radial distributions: the transformation of phase 6 in phase 7 is easier to proceed and therefore no peak corresponding to this reaction is found in the derivative curve. This confirms the observation made from their lithium uptake values. From these results, we can conclude that most likely the reaction intermediates are different depending on $\mathrm{FeF}_{3}$ sample and we propose the following final diagram: 


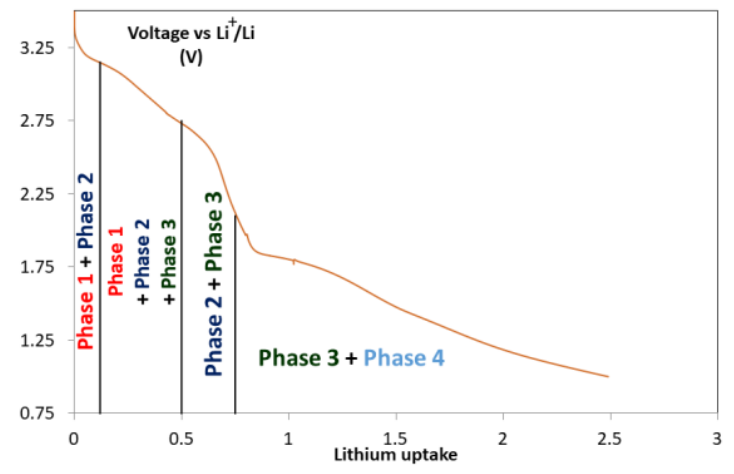

Scheme 1: Proposed schematic phase evolution during the discharge process of $r-\mathrm{FeF}_{3}$

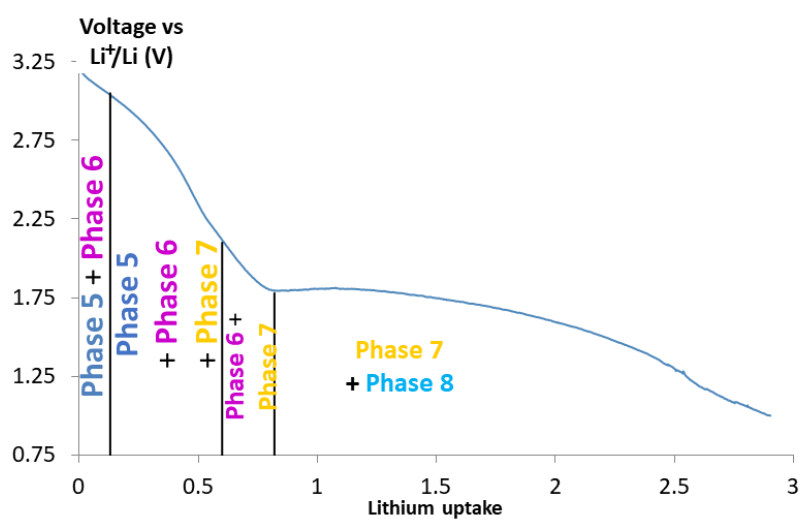

Scheme 2: Proposed schematic phase evolution during the discharge process of pyr- $-\mathrm{FeF}_{3}$

\section{Conclusions}

Thanks to a straightforward gas-solid fluorination method, we were able to synthesize two anhydrous $\mathrm{FeF}_{3}$ with specific electrochemical behavior when used as cathode material in lithium ion battery. From crystallographic point of view, those two samples are mainly composed of either a cubic structure called pyrochlore or a rhombohedral structure.

A complete study of the structure and the composition of both samples was achieved by performing XRD, Mössbauer and PDF analyses. Both samples could be treated as pure phase samples for MCR-ALS treatment as XANES spectra of HTB and pyr- $\mathrm{FeF}_{3}$ appear as very close.

We were able to monitor the entire lithiation process of both compounds with excellent time resolution. An interesting computing method called Multivariate Curve Resolution with Alternating Least Squares (MCR-ALS) was used as chemometric method to screen the steady-state composition of the system studied. This enabled a revamping of some previous statements as well as rationalizing the data from electrochemistry and from the local environment of iron atoms, this by processing back and forth between the different data sources.

For both samples, 4 phases were obtained to describe the entire lithiation. Systematically, a decrease in the intensity of the second coordination sphere was observed in the radial distribution of the phases. This could be due to the grinding effect of lithiation of $\mathrm{FeF}_{3}$ taking place at the global scale as evidenced by the amorphization but also at the local scale, causing a loss of information from the second coordination shell.

Results also highlighted the presence of different reaction intermediates. Indeed, the intermediates for $r-F_{3} F_{3}$ seem to be very similar in their local structure while this is not observed in pyr-FeF . More importantly, the last phase formed in the case of the rhombohedral sample is close to metallic iron whereas it has a very different local structure in the case of pyr- $-\mathrm{FeF}_{3}$. This directly affects the electrochemical performances as pyr-FeF $\mathrm{F}_{3}$ was unable to achieve a complete three electron exchange for a cut-off of $1 \mathrm{~V}$. This was confirmed by MCR-ALS as the last phase formed for this sample presents a pseudo radial distribution close to the ones for previous intermediates formed but contains a new peak which could be assigned to metallic iron. According to literature, the differences observed 
between our samples could originate from the morphology changes upon insertion and almost conversion. Real time monitoring of this aspect should be addressed.

As a result, the discharge of pyr- $\mathrm{FeF}_{3}$ sample goes through more interesting intermediates to enable a higher insertion voltage than the $r-\mathrm{FeF}_{3}$ sample but $\mathrm{r}-\mathrm{FeF}_{3}$ is the sample of choice if the application aims at targeting high capacity values.

\section{Experimental}

\section{Materials synthesis}

Direct gas fluorination process was performed in a dedicated fluorine device using special handling procedures. Gaseous fluorine was purchased from Solvay Fluor (purity $98-99 \% \mathrm{v} / \mathrm{v}$ with HF max. 0.5\% v/v and other gases, primarily $\mathrm{O}_{2} / \mathrm{N}_{2}$ at about $0.5 \% \mathrm{v} / \mathrm{v}$ ). A $1 \mathrm{~L}$ cylindrical nickel reactor of approximately $50 \mathrm{~cm}$ of length has been used for the reaction. A horizontal tubular oven with a $10 \mathrm{~cm}$ domain of homogeneous temperature was surrounding the reactor to ensure the heating of the reactor. Each sample was set in a $10 \mathrm{~cm}$ long passivated nickel basket. Before and after fluorination treatment, the reactor was passed by pure nitrogen in order either to remove water molecules, oxygen traces at the beginning of the process or fluorides residues at the end of the process.

Pyr- $\mathrm{FeF}_{3}$ has been obtained starting from $1 \mathrm{~g}$ of $\mathrm{NH}_{4} \mathrm{Fe}_{2} \mathrm{~F}_{6}$ following the as-described process : 1 hour at $100^{\circ} \mathrm{C}$ under a flux of pure nitrogen $(100 \mathrm{~mL} / \mathrm{min})$, then $30 \mathrm{~min}$ at $200^{\circ} \mathrm{C}$ still under nitrogen and finally $2 \mathrm{~h}$ at $200^{\circ} \mathrm{C}$ under a flux of pure molecular fluorine set at $40 \mathrm{~mL} / \mathrm{min}$.

The following reaction occurs :

$\mathrm{NH}_{4} \mathrm{Fe}_{2} \mathrm{~F}_{6}+0.5 \mathrm{~F}_{2} \rightarrow 2 \mathrm{FeF}_{3}+\mathrm{NH}_{4} \mathrm{~F}$

Among the three crystallographic phase of $\mathrm{FeF}_{3}$, pyrochlore phase is the low temperature phase that transforms into $\mathrm{HTB}$ at $280^{\circ} \mathrm{C}$ under gaseous fluorination. The high temperature phase is the rhombohedral one stabilized at $350^{\circ} \mathrm{C}^{4}$.

$\mathrm{r}-\mathrm{FeF}_{3}$ has been obtained starting from $1 \mathrm{~g}$ of $\mathrm{FeCl}_{3}, 6 \mathrm{H}_{2} \mathrm{O}$ following the as described process : 6 hours at $600^{\circ} \mathrm{C}$ under a flux of pure molecular fluorine set at $40 \mathrm{~mL} / \mathrm{min}$.

The following reaction occurs :

$$
2 \mathrm{FeCl}_{3} \cdot 6 \mathrm{H}_{2} \mathrm{O}+3 \mathrm{~F}_{2}->2 \mathrm{FeF}_{3}+3 \mathrm{Cl}_{2}+12 \mathrm{H}_{2} \mathrm{O}
$$

\section{X-ray powder diffraction analysis}

X-ray powder diffraction (XRD) experiments were carried out on a Panalytical X-Pert Pro diffractometer equipped with a diffracted beam monochromator $\mathrm{Cu} \mathrm{K} \alpha 1$ source and a X'celerator linear detector by using a homemade measurement cell. This set up allows the data to be collected under a static inert argon atmosphere. The counting time was fixed at 200 s and the angle step size was of about $0.0836^{\circ}$ in $10-90^{\circ} 2$-theta range.

\section{${ }^{57}$ Fe room temperature Mössbauer analysis}

Mössbauer spectroscopy has been measured on freshly prepared samples stored under argon. 57Fe Mössbauer spectra were recorded in the constant acceleration mode and in transmission geometry on a standard Mössbauer spectrometer composed of electronic devices from Ortec and Wissel. A ${ }^{57} \mathrm{Co}(\mathrm{Rh})$ source with a nominal activity of $370 \mathrm{MBq}$ was used. The source and the absorber were always kept at room temperature. The thickness of the absorbers is about $10 \mathrm{mg} . \mathrm{cm}-2$. The isomer shift is given relative to $\alpha$-Fe standard at room temperature.

\section{Pair distribution function analysis}

Total X-ray scattering data were collected at SOLEIL synchrotron on the X-ray powder diffraction station of Cristal beamline in Debye-Scherrer mode. The wavelength, $0.436723 \AA$ ( $28 \mathrm{keV}$ ), was selected with a double-crystal Si (111) monochromator and determined from a $\mathrm{LaB}_{6}$ NIST standard measurement. The diffractometer was equipped with a XPAD hybrid pixel detector especially suited for acquiring extremely good signal-to-noise ratio and timeresolved and data sets. The powder samples were packed in glass capillaries which were $0.7 \mathrm{~mm}$ in diameter. Data were collected at room temperature, in the $1-125^{\circ}$ angular range with a total acquisition time of $30 \mathrm{~min}$.

The two dimensional raw data were converted to intensity versus $2 \theta$. The data were corrected and normalized using the program PDFget $X 2^{35}$ and truncated at $Q_{\max }=25 \AA^{-1}$ to obtain the optimized total scattering structure function $S(Q)$ and the PDF $G(r)$. Structural and quantitative phase analysis information was obtained from the PDF data using the PDFgui software ${ }^{36}$. Final global optimized parameters were: scale factors, cell parameters, atomic positional coordinates and atomic displacement parameters ADPs. Moreover, the low-r correlated motion peak sharpening factor (sratio/ rcut) ${ }^{37}$ was refined. The instrumental parameters were obtained by measuring a similar data set for crystalline $\mathrm{Fel}_{2}$ (ICSD\#52369). $\mathrm{Fel}_{2}$ PDF data analysis converged to Qdamp $=0.079 \AA^{-1}$. 


\section{Electrochemical experiments}

Each electrochemical test was performed at $60^{\circ} \mathrm{C}$ to improve lithium diffusion at the first cycle. $\mathrm{FeF}_{3}$ has been milled for $6 \mathrm{~h}$ at $350 \mathrm{rpm}$ with acetylene black in a 50:50 $(\mathrm{w} / \mathrm{w})$ ratio to increase conductive properties of the final electrode. Electrode material was prepared by mixing the grinded material with a polyvinylidene fluoride binding agent in an argon-filled glove box. The resulting mixture was then stirred with propylene carbonate until good mechanical properties were obtained. Afterward, it was deposited on graphitic foil and dried. This graphitic foil avoid the use of lower cutoff voltage than $1 \mathrm{~V}$ to prevent from its reduction mechanism.

A $5 \mathrm{~h}$ relaxation was performed until circuit voltage stabilization. Galvanostatic measurements were then carried out with the different $\mathrm{FeF}_{3}$ obtained after fluorination with current densities of $\mathrm{C} / 24$ ( $\mathrm{C}=712 \mathrm{mAh} \cdot \mathrm{g}^{-1}$, theoretical capacity of the whole 3 electron process) for the discharge. Cut-off voltage in discharge was set at $1 \mathrm{~V}$ and voltage was registered each 30 s in the meantime

Additional information on the electrochemical cell used can be found in Leriche et al. work ${ }^{33}$.

\section{Operando XAS}

XAS experiments were performed on ROCK beamline on SOLEIL synchrotron. The current of the machine was 450 $\mathrm{mA}$ in hybrid Top-up mode. ROCK ${ }^{38}$ is a beamline dedicated to operando XAFS thanks to two quick EXAFS monochromators which the hard X-Ray photons come from a bending magnet. The beam is horizontally focalized thanks to a toroidal Ir coated mirror, the harmonics were removed thank to two mirrors tiled at $3.5 \mathrm{mrad}$ and we used the $\mathrm{B}_{4} \mathrm{C}$ stripes. We use the $\mathrm{Si}(111)$ quick EXAFS monochromator and the beam size was $2.5 \mathrm{~mm}$ in horizontal and $0.650 \mathrm{~mm}$ in vertical at the sample position. The oscillation speed of the monochromator was $2 \mathrm{~Hz}$ at the Fe $\mathrm{K}$ edges enabling the collection of one full EXAFS spectrum in $250 \mathrm{~ms}$. The signal was collecting in transmission utilizing gas ionization chambers as detectors and these three detectors in series allow the simultaneous recording of a Fe metal foil which was used as reference to calibrate the energy for each spectrum. 2 points were collecting on each sample, meaning two points on each electrode during their functioning, to ensure the repeatability of the measurements. The effective sampling is considered as 30 s and is perfectly in line the voltage measurement which also occur each 30s.

As a consequence, the spectra were recorded every $0.5 \mathrm{~min}$ with a galvanostatic cycling regime of $\mathrm{C} / 24$ (1 $\mathrm{Li}^{+}$reacted in 24h). In this way, every spectrum represents the average reaction of $0.0004 \mathrm{Li}^{+}$. If any particular variation occurs upon 30 s owing to galvanostatic measurement, we are to able access to its spectra.

The energy calibration and the normalization were done using graphical interfaces available on the ROCK beamline $^{39}$. The Fourier transformation as well as the extended X-ray absorption fine structure (EXAFS) analysis was performed using the Demeter package ${ }^{40}$.

XAS spectra were deconvoluted using mathematic tools obtained by the combination of Principal Component Analysis (PCA) and Multivariate Curve Resolution with Alternating Least Squares (MCR-ALS).The unique solution respecting the applied constraints gives the access to the XAS spectra of the four pure components and their relative concentration evolution. Information such as the corresponding Fourier transformation of the EXAFS part (FT-EXAFS) and the resulting pseudo radial distribution for each modelled phase can also be extracted.

\section{Conflicts of interest}

The authors of this article have no conflicts of interest to declare.

\section{Acknowledgements}

This work was supported by a public grant overseen by the French National Research Agency (ANR) as part of the "Investissements d'Avenir" program (reference : ANR-10-EQPX-45)

The authors want to thank V. MAISONNEUVE from Le Mans for providing precursor of pyrochlore phase, $P$. $B O N N E T, M$. EL-GHOZZI and E. DISA from ICCF from experimental helps.

\section{Notes and references}


2 N. Nitta, F. Wu, J. T. Lee and G. Yushin, Materials Today, 2015, 18, 252-264.

3 D. E. Conte and N. Pinna, Materials for Renewable and Sustainable Energy, , D0I:10.1007/s40243-014-0037-2.

$4 \quad$ L. Francke, 2002.

5 Q. Zhang, C. Sun, L. Fan, N. Zhang and K. Sun, Chemical Engineering Journal, 2019, 371, $245-251$.

6 J. Zhai, Z. Lei, D. Rooney, H. Wang and K. Sun, Journal of Power Sources, 2018, 396, 371-378.

7 X. Zhou, J. Ding, J. Tang, J. Yang, H. Wang and M. Jia, Journal of Electroanalytical Chemistry, 2019, 847, 113227.

8 J. Zhai, Z. Lei, D. Rooney and K. Sun, Electrochimica Acta, 2019, 313, 497-504.

9 D. Qiu, L. Fu, C. Zhan, J. Lu and D. Wu, ACS Appl. Mater. Interfaces, 2018, 10, 29505-29510.

10 Y. Shen, X. Wang, H. Hu, M. Jiang, X. Yang and H. Shu, Journal of Power Sources, 2015, 283, $204-210$.

11 R. S. Rao, V. Pralong and U. V. Varadaraju, Materials Letters, 2016, 170, 130-134.

12 G. Ali, G. Rahman and K. Y. Chung, Electrochimica Acta, 2017, 238, 49-55.

13 K. Guérin, D. Delbègue, N. Louvain, L. Doubtsof, A. Hamwi, B. Laik, J.-P. Pereira-Ramos, M. Tahar-sougrati, J.-C. Jumas, P. Willmann and C. Cénac-Morthe, Materials Chemistry and Physics, 2016, 173, 355-363.

14 Z. Gong and Y. Yang, Journal of Energy Chemistry, 2018, 27, 1566-1583.

15 G. Chen, X. Zhou, Y. Bai, Y. Yuan, Y. Li, M. Chen, L. Ma, G. Tan, J. Hu, Z. Wang, F. Wu, C. Wu and J. Lu, Nano Energy, $2019,56,884-892$.

16 V. Murugesan, J. S. Cho, N. Govind, A. Andersen, M. J. Olszta, K. S. Han, G. Li, H. Lee, D. M. Reed, V. L. Sprenkle, S. Cho, S. K. Nune and D. Choi, ACS Appl. Energy Mater., 2019, 2, 1832-1843.

17 H. J. Tan, H. L. Smith, L. Kim, T. K. Harding, S. C. Jones and B. Fultz, Journal of the Electrochemical Society, 2014, 161, A445-A449.

18 G. Ali, J. Lee, W. Chang, B.-W. Cho, H.-G. Jung, K.-W. Nam and K. Y. Chung, Sci Rep, $2017,7,42237$.

19 D. E. Conte, L. Di Carlo, M. T. Sougrati, B. Fraisse, L. Stievano and N. Pinna, J. Phys. Chem. C, 2016, 120, 2393323943.

20 R. E. Doe, K. A. Persson, Y. S. Meng and G. Ceder, Chem. Mater., 2008, 20, 5274-5283.

21 L. Li, R. Jacobs, P. Gao, L. Gan, F. Wang, D. Morgan and S. Jin, Journal of the American Chemical Society, 2016, 138, $2838-2848$.

22 L. Li, Y. K. Chen-Wiegart, J. Wang, P. Gao, Q. Ding, Y.-S. Yu, F. Wang, J. Cabana, J. Wang and S. Jin, Nat Commun, $2015,6,6883$.

23 W. Zhang, P. N. Duchesne, Z.-L. Gong, S.-Q. Wu, L. Ma, Z. Jiang, S. Zhang, P. Zhang, J.-X. Mi and Y. Yang, J. Phys. Chem. C, 2013, 117, 11498-11505.

24 H. Arai, S. Okada, Y. Sakurai and J. Yamaki, Journal of Power Sources, 1997, 68, 716-719.

25 P. Conti, S. Zamponi, M. Giorgetti, M. Berrettoni and W. H. Smyrl, Anal. Chem., 2010, 82, 3629-3635.

26 W. H. Cassinelli, L. Martins, A. R. Passos, S. H. Pulcinelli, C. V. Santilli, A. Rochet and V. Briois, Catalysis Today, 2014, 229, 114-122.

27 D. L. Massart, B. G. M. Vandeginste, L. M. C. Buydens, S. D. Jong, P. J. Lewi and J. Smeyers-Verbeke, in Handbook of Chemometrics and Qualitmetrics: Part A, Elsevier, Amsterdam, 1997.

28 M. Garrido, M. S. Larrechi, F. X. Rius and R. Tauler, Chemometrics and Intelligent Laboratory Systems, 2005, 76, 111-120. 
69, 197-201.

31 Y. Calage, M. Leblanc, G. Ferey and F. Varret, Journal of Magnetism and Magnetic Materials, 1984, 43, $195-203$.

32 F. Cosandey, J. F. Al-Sharab, F. Badway, G. G. Amatucci and P. Stadelmann, Microscopy and Microanalysis, 2007, 13, 87-95.

33 J. B. Leriche, S. Hamelet, J. Shu, M. Morcrette, C. Masquelier, G. Ouvrard, M. Zerrouki, P. Soudan, S. Belin, E. Elkaïm and F. Baudelet, J. Electrochem. Soc., 2010, 157, A606.

34 R. De Pape and G. Ferey, Materials Research Bulletin, 1986, 21, 971-978.

35 C. L. Farrow, P. Juhas, J. W. Liu, D. Bryndin, E. S. Božin, J. Bloch, T. Proffen and S. J. L. Billinge, J. Phys.: Condens. Matter, 2007, 19, 335219.

36 X. Qiu, J. W. Thompson and S. J. L. Billinge, J App/ Crystallogr, 2004, 37, 678-678.

37 I.-K. Jeong, R. H. Heffner, M. J. Graf and S. J. L. Billinge, Phys. Rev. B, 2003, 67, 104301.

38 V. Briois, C. La Fontaine, S. Belin, L. Barthe, T. Moreno, V. Pinty, A. Carcy, R. Girardot and E. Fonda, J. Phys.: Conf. Ser., 2016, 712, 012149.

39 C. Lesage, E. Devers, C. Legens, G. Fernandes, O. Roudenko and V. Briois, Catalysis Today, 2019, 336, 63-73.

40 B. Ravel and M. Newville, J Synchrotron Rad, 2005, 12, 537-541. 